Stervid, B. T. - Do texto ao contexto

\title{
Do texto ao contexto: uma análise comparativa das abordagens descritiva e funcional dos
} Estudos da Tradução

[From text to context: a comparative analysis of the descriptive and functional approaches of Translation Studies]

http://dx.doi.org/10.11606/1982-883723391

Beatriz Terreri Stervid ${ }^{1}$

\begin{abstract}
The descriptive and functional approaches of Translation Studies contributed to the socalled "cultural turn" by proposing non-prescriptive ways of approaching translation and redirecting the study focus to the reception context. This paper provides a comparative analysis of the main aspects of these approaches, identifying common points and divergences in their theories. We start by analyzing its general proposals and then by comparing the main contributions of Gideon Toury and Christiane Nord to Translation Studies, in order to better understand the two proposals. Finally, we investigate the application of functionalist and discriptivist theories in translation research, based on the analysis of theses and dissertations.
\end{abstract}

Keywords: translation studies; functionalism; descriptivism.

Resumo: As abordagens descritiva e funcional dos Estudos da Tradução contribuíram para o que se convencionou chamar de "virada cultural" ao propor formas não prescritivas de abordar a tradução e redirecionar o foco do estudo para o contexto de recepção. Analisamos neste artigo alguns dos principais aspectos das abordagens, a fim de localizar pontos em comum e divergências em suas teorias. Partiremos da análise de suas propostas gerais e, em seguida, será feita a comparação das principais contribuições de Gideon Toury e Christiane Nord aos Estudos da Tradução, buscando compreender melhor as propostas das duas vertentes. Por fim, trataremos da aplicação das teorias descritivistas e funcionalistas nas pesquisas sobre tradução, com base na análise de dissertações e teses.

Palavras-chave: estudos da tradução; funcionalismo; descritivismo.

\section{A "virada cultural" com os estudos descritivos e funcionais da tradução}

\footnotetext{
${ }^{1}$ Universidade de São Paulo, Rua do Lago, 717, Cidade Universitária, Butantã, São Paulo, SP, 05508-900, Brasil. E-mail: beatrizstervid@ @mail.com. ORCID: 0000-0002-6105-3988
}

(cc) BY-NC

Pandaemonium, São Paulo, v. 23, n. 39, jan.-abr. 2020, p. 1-24 
Stervid, B. T. - Do texto ao contexto

$\mathrm{Na}$ tentativa de se enquadrar ao rigor do estudo científico, a pesquisa acadêmica sobre tradução adotou, inicialmente, os pressupostos e métodos da linguística estrutural, de forma a ignorar aspectos subjetivos e variáveis extralinguísticas da constituição dos textos. A pesquisa sobre tradução literária tinha como parâmetro principal o texto de partida, à qual não raras vezes subjazia a ideia de um original intraduzível. Assim, as análises de traduções se limitavam, predominantemente, a detectar seus defeitos e reafirmar a supremacia do texto original. Com o questionamento da noção de equivalência, bem como da posição de isenção do tradutor no processo tradutório, preconizado principalmente pelos desconstrutivistas, abrem-se as portas para novas abordagens que levem em conta questões que vão além da superfície linguística dos textos, como aspectos culturais, sociais e históricos da produção do texto de chegada (cf. AZENHA JUNIOR 2010 e CRUZ 2012).

Desta forma, diante das limitações das abordagens prescritivas no estudo sobre tradução, foi desenvolvida na década de 1970 e consolidada na década seguinte uma vertente descritiva e sistêmica, chamada de "Estudos Descritivos da Tradução" (Descriptive Translation Studies), que ficou conhecida mais tarde como um "novo paradigma" no estudo de literatura traduzida (cf. HERMANS 1999). Essa nova forma de abordar o fenômeno tradutório era defendida por um grupo de pesquisadores que tinham em comum

[...] uma visão de literatura como sistema complexo e dinâmico; uma convicção de que deveria haver uma interação contínua entre modelos teóricos e estudos práticos de caso; uma abordagem à tradução literária que é descritiva, orientada ao texto-alvo, funcional e sistêmica; e um interesse nas normas e condicionantes que governam a produção e recepção de traduções, na relação entre tradução e outros tipos de processamento de texto, e na posição e papel das traduções tanto dentro de uma determinada literatura quanto na interação entre literaturas. (HERMANS 1985: 10-11, tradução nossa)

Há, portanto, uma mudança de um "olhar retrospectivo", voltado aos aspectos do texto de partida e à necessidade de "equivalência" na tradução, para um "olhar prospectivo", voltado às "normas e convenções da cultura receptora", de forma a redefinir a ênfase de análise para o contexto de recepção da tradução (AZENHA JUNIOR 2010: 40). Ao assumir essa perspectiva, questões relacionadas ao modo como a tradução funciona na sociedade e ao impacto que ela exerce no contex to de recepção, assim como às leituras 
Stervid, B. T. - Do texto ao contexto

que são feitas a partir dela em determinada cultura, passam a ser objetos centrais da pesquisa sobre tradução.

Entretanto, essa não foi a única proposta responsável pela transferência do foco dos estudos sobre tradução para a recepção. Também na década de 1970 começara a ser desenvolvida na Alemanha uma vertente funcional que propunha um redirecionamento do olhar para a cultura do texto de chegada, acentuando que o principal no processo tradutório não é a tentativa de alcançar equivalência em relação ao texto de partida, mas sim de cumprir com seu propósito comunicativo.

Consequentemente, um mesmo texto de partida pode ser traduzido de várias maneiras, a depender da função que deve exercer no contexto de recepção. Assim, as primeiras teorias da abordagem funcional, notadamente a teoria do escopo (Skopostheorie) de Vermeer, são consideradas um marco nos Estudos da Tradução, por propor uma alternativa à noção de equivalência:

Neste modelo, língua não é um "sistema" autônomo, mas parte de uma cultura. Portanto, o tradutor não deveria ser apenas bilíngue, mas também bicultural. De forma semelhante, o texto não é um fragmento linguístico estático e isolado, mas, ao contrário, depende de sua recepção pelo leitor e possui, invariavelmente, uma relação com a situação extralinguística na qual está inserido. [...] Essa abordagem relativiza tanto o texto quanto a tradução: a única e perfeita tradução não existe. Toda tradução depende de seu escopo (skopos) e de sua situação. (SNELL-HORNBY 2006: 52, tradução nossa)

Portanto, ambas as abordagens contribuíram para aquilo que se convencionou chamar de "virada cultural", ao propor formas não prescritivas de abordar a tradução e redirecionar o foco do estudo para o contexto de recepção. Porém, cada uma delas tem suas particularidades e enfoques específicos. A abordagem descritiva, principalmente com Gideon Toury, Itamar Even-Zohar e André Lefevere, concentra-se em questões relativas à tradução literária, como, por exemplo, os sistemas literários da cultura receptora e suas normas e convenções. Já o funcionalismo, através da teoria do Skopos de Hans Vermeer, ficou conhecido por se concentrar mais em textos de especialidades e lidar com questões ligadas à formação de tradutores, cabendo a Christiane Nord divulgar a aplicabilidade das teorias funcionalistas também no domínio da tradução literária.

Apesar das duas vertentes ocuparem posição de destaque nos Estudos da Tradução, as contribuições dadas pelo funcionalismo se concentraram mais nos países de língua alemã, já que a divulgação em língua inglesa ainda é restrita. Talvez por esse motivo, houve um uso exacerbado de fontes indiretas em livros introdutórios sobre 
Stervid, B. T. - Do texto ao contexto

tradução no trato com as teorias funcionalistas, o que contribuiu para os inúmeros equívocos acerca dessa abordagem (MOREIRA 2014: 18), inclusive na sua relação com as teorias descritivistas, sendo muitas vezes tratadas como abordagens divergentes, embora seja possível localizar vários pontos de contato. Julgamos necessário, portanto, analisar algumas das contribuições mais relevantes das duas vertentes, a fim de compreender quais pontos as aproximam e quais são aqueles que as diferem uma da outra.

Deste modo, buscaremos localizar as semelhanças e diferenças das abordagens, primeiramente através da análise de suas propostas gerais e, em seguida, pela comparação das principais contribuições de Gideon Toury e Christiane Nord aos Estudos da Tradução. Esperamos, com isso, compreender melhor as propostas das duas vertentes, não somente com o objetivo de localizar as particularidades de cada uma, mas também a aplicação de suas teorias nas pesquisas sobre tradução.

\section{Propostas gerais e principais teorias}

Vimos que a vertente descritiva surge em meados da década de 1970, especialmente em Leuven (Bélgica), Amsterdã (Holanda) e Tel Aviv (Israel), como uma proposta de investigação dos aspectos culturais e sociais que estão envolvidos no processo tradutório, de modo a deixar para trás uma visão limitada segundo a qual o único fator determinante da tradução seria o texto de partida: "Pesquisas descritivas orientavam-se veementemente tanto contra a redução, comum na época, da tradução a uma operação meramente linguística, como também contra o foco prescritivo e voltado à prática, dado pela pesquisa aplicada" (HERMANS in SNELL-HoRnBy 2015: 97). Assim, procurava-se descrever, por meio de novas teorias e metodologias, o funcionamento da tradução em seu contexto de recepção.

Entre as principais teorias desenvolvidas nessa época está a "teoria dos polissistemas" (polysystem theory), elaborada pelo pesquisador israelense Itamar EvenZohar. O "polissistema literário" pode ser entendido como um sistema dinâmico e heterogêneo formado por um conjunto de relações entre diversos subsistemas, no qual a literatura traduzida é tida como um deles, ao lado das outras formas de literatura canônica e não canônica (cf. EvEn-ZoHAR 2013). Com essa teoria, como aponta Munday (2008: 
Stervid, B. T. - Do texto ao contexto

108), é conferida à tradução, antes tida como algo secundário e até mesmo inferior, uma posição relevante ao lado de outras formas de literatura.

A consolidação dos Estudos Descritivos da Tradução foi levada a cabo principalmente por Gideon Toury, que trabalhava ao lado de Even-Zohar em Israel. Em sua obra Descriptive Translation Studies and Beyond, de 1995, Toury parte da proposta de Holmes exposta em 1972 no texto "The Name and Nature of Translation Studies" (2004), uma das primeiras tentativas de elaboração de uma disciplina autônoma sobre tradução, para defender o desenvolvimento da vertente descritiva dessa disciplina a partir da aplicação sistemática, em estudos empíricos, de uma metodologia de análise descendente (top-down). Esse tipo de análise, comum às metodologias descritivistas, começa "com fatores sistêmicos mais gerais (em especial construtos como a posição das traduções dentro de um sistema sociocultural) e descem para fatores mais específicos (em especial, categorias como estratégias de tradução)" (РYM 2017: 135).

Uma importante contribuição de Toury está na noção de "normas de tradução" (translational norms). Segundo o autor, todo processo tradutório, assim como a recepção do texto traduzido, é norteado por normas tidas como valores e ideias compartilhados por uma comunidade quanto ao que é adequado ou não em determinada situação (ToURY 2012: 81). Os estudos de caso teriam como objetivo fazer generalizações em relação ao processo de tomada de decisões do tradutor e então reconstruir as normas que operam na tradução, de forma a formular hipóteses a serem testadas em outros estudos descritivos (cf. MundAY 2008: 111).

As noções de reescrita (rewriting) e patronagem (patronage) de Lefevere (1992) também são importantes contribuições à vertente descritiva, visto que procuram explicar como funciona a manipulação da literatura por meio da tradução, dando enfoque à atuação de instituições e agentes, como críticos e editores: as reescrituras, que consistem de todo produto de leituras de obras literárias, inclusive as próprias traduções, são consideradas formas de manipulação da literatura e, consequentemente, de direcionamento de sua recepção, porquanto têm a capacidade de manipular as percepções sobre ela. Já o conceito de patronagem se refere ao poder de pessoas e instituições que atuam na reescrita da literatura. 
Stervid, B. T. - Do texto ao contexto

Portanto, as teorias propostas no interior dessa vertente têm como função auxiliar na descrição de traduções, porém não de forma puramente linguística, em função do texto de partida, mas sim em função da situação de recepção. O objetivo não é, deste modo, o treinamento de tradutores ou a crítica de tradução, mas sim a compreensão, por meio de descrições, do fenômeno tradutório em meio à cultura receptora. Já a vertente funcional, como veremos, apesar de ter partido de um mesmo impulso contra o tratamento à tradução voltado ao texto de partida, faz uso das teorias funcionalistas em prol da melhoria da prática tradutória e da crítica especializada.

Moreira (2014: 118) aponta para uma crise na chamada "Ciência da Tradução" (Übersetzungswissenschaft) como ponto de partida para formulação da "Teoria Funcional". Segundo ele, as divergências teóricas e metodológicas, bem como sua posição marginal ocupada dentro da Linguística, levaram a um questionamento da legitimidade desse campo de estudos. A isso se acrescia o distanciamento entre os planos teórico e didático, causado em parte pelas controvérsias nas universidades e institutos de formação. A abordagem funcional teria surgido da tentativa de resolver esse conflito:

A crise nos âmbitos teórico e didático levaram docentes de universidades no sul da Alemanha Ocidental a conceber modelos que combinassem formação prática e reflexão teórica. Pesquisadores das Universidades de Mainz e de Heidelberg deram desenvolvimento, em torno da figura de Hans J. Vermeer, à abordagem funcional a partir do final dos anos de 1970. Além de se constituírem como grupo, esses teorizadores também criaram os meios para que suas ideias circulassem ao menos regionalmente. (MOREIRA 2014: 146)

Uma das primeiras e fundamentais teorias da vertente funcional é a teoria do escopo (elaborada por Hans Vermeer em 1978 e apresentada em detalhes pela primeira vez em 1984, na obra Grundlegung einer allgemeinen Translationstheorie, publicada em coautoria de Katharina Reiss), de modo que essa abordagem também ficou conhecida como Skopostheorie. Valendo-se ora da palavra de origem grega Skopos, ora da palavra alemã Zweck (propósito), a teoria do escopo assinala a tradução como uma ação guiada por um propósito. Assim como qualquer atividade humana na qual indivíduos desempenham papeis específicos, também na produção textual (como no caso da tradução) a ação dos agentes da comunicação é marcada por um propósito, um objetivo, e o texto deve ser considerado portador de uma função a ser desempenhada na situação comunicativa (cf. REISS, VERMEER 2014: 90). 
Stervid, B. T. - Do texto ao contexto

Considerando que todo produto da ação tradutória (translatum) é uma oferta de informação sobre uma língua e cultura de partida para uma língua e cultura de chegada, as estratégias de tradução adotadas devem estar de acordo com a função dessa informação (2014). Portanto, a tradução é considerada um "fenômeno no qual a estratégia e a forma da tradução dependem do propósito da ação tradutória” (2014: 79, tradução nossa).

As ideias trazidas através da teoria do escopo seriam posteriormente expandidas por outros teóricos, ainda no contexto de língua alemã, como Justa Holz-Mänttäri (1984), que desenvolve o conceito de "ação tradutória" (Translatorisches Handeln), definida como "uma ação complexa designada para alcançar um determinado propósito" (apud NORD 2007: 13, tradução nossa). Ela enfatiza aspectos comunicativos do processo tradutório, analisando o papel de participantes (como iniciador, tradutor, usuário, receptor da mensagem) e as condições da situação (tempo, espaço e meio) na qual suas atividades são realizadas (cf. NORD 2007: 13).

De forma semelhante às normas de tradução de Toury, na teoria do escopo também estão previstas regras na transmissão de informação que são específicas às culturas, às línguas e às funções (2014: 79). Deste modo, assim como a abordagem descritiva, a abordagem funcional também é guiada por uma orientação prospectiva, ou seja, voltada para o contexto de recepção da tradução. Porém, em sua explicação da teoria do escopo, Vermeer acentua: "Diferentemente de Toury, nós acreditamos que a tradução é um fenômeno tanto da cultura de partida quanto de chegada. Ele começa na cultura de partida e pode ainda ter um impacto direto ou indireto nessa cultura" (2014: 74, tradução nossa). Como exemplo desse impacto, é citada a influência, na literatura dinamarquesa, das traduções alemãs dos contos de fada de Christian Andersen. Apesar de Toury também apontar para essa possibilidade, ele acentua que não são todas as traduções que podem exercer influência no texto e contexto de partida, sendo isso antes uma exceção do que uma regra (cf. 2012: 21).

Entretanto, vale acentuar que, mesmo que Toury tenha proposto o estudo da tradução como um fato da cultura receptora (cf. 2012: 17-18), isso não significa necessariamente um total esquecimento do texto e cultura de partida, mas sim uma resposta à necessidade de se dar mais enfoque às condicionantes da cultura receptora, antes quase totalmente desconsideradas. Da mesma forma, por mais que Vermeer tenha 
Stervid, B. T. - Do texto ao contexto

assinalado a necessidade de considerar o contexto de partida, sua teoria é essencialmente "prospectiva" ${ }^{2}$, cabendo a outros teóricos a formulação de propostas mais direcionadas para uma posição intermediária, não tão rigorosamente oposta às abordagens "retrospectivas".

Entre os teóricos atualmente ativos que se inserem no domínio da abordagem funcional está Christiane Nord (Universidade de Heidelberg), importante divulgadora do funcionalismo. Ela dedica-se principalmente às questões ligadas ao treinamento de tradutores, através da aplicação das teorias funcionalistas à prática tradutória. Na obra Textanalyse und Übersetzen (“Análise textual e tradução"), publicada pela primeira vez em 1988, a autora apresenta um modelo de análise que tem como objetivo auxiliar o tradutor no processo de tradução, mais propriamente na análise do conteúdo e das características estilísticas do texto-fonte, pertencente a qualquer gênero textual (inclusive literário), de forma a compreendê-lo de forma funcional. Assim, essa análise seria feita tendo em vista não somente aspectos do texto de partida, mas também tendo como base o propósito e contexto da tradução.

Segundo a autora, esse método surge da necessidade de um modelo de análise que leve em consideração o processo tradutório e dê um embasamento para cada escolha de tradução, substituindo o uso de modelos importados de outras áreas, como a teoria literária. Trata-se de um modelo geral que pretende dar conta de diversos tipos de problemas na tradução, de ordem cultural, linguística e comunicativa, independentemente do par de línguas envolvido na tradução (cf. NORD 2009: 2).

Nas considerações teóricas que fundamentam seu método (cf. NORD 2009: 4-23), Nord aponta para o fato de que não é a função e recepção do texto de partida que determina o processo de tradução, mas sim a função da tradução estabelecida pelo iniciador da tradução (um editor, por exemplo). Ela enfatiza a importância de saber aspectos da recepção para que se possa melhor fazer escolhas no processo de tradução. Além disso, a leitura do tradutor não é uma leitura ingênua, mas sim analítica, voltada

\footnotetext{
${ }^{2}$ Logo após fazer a observação citada sobre o posicionamento de Toury, Vermeer reafirma o conceito de tradução como uma oferta de informação na cultura receptora: "Tradução como uma oferta de informação é essencialmente dependente da situação de recepção (mais especificamente, das expectativas em relação à situação de recepção) e, portanto, da cultura e língua de chegada" (2014: 74). Fica evidente que, semelhante a Toury, sua posição é "prospectiva", orientada ao alvo (target-oriented).
}

Pandaemonium, São Paulo, v. 23, n. 39, jan.-abr. 2020, p. 1-24 
Stervid, B. T. - Do texto ao contexto

tanto para as condições de produção do texto de partida, quanto para as condições do contexto de chegada.

Portanto, percebe-se, primeiramente, que Nord procura com seu método seguir o "caminho do meio" entre um olhar para o texto e contexto de partida e um olhar para a recepção da tradução. Seu método, que tem como base as teorias funcionalistas (algumas propostas por ela, como o conceito de lealdade), é uma aplicação no treinamento de tradutores das ideias desenvolvidas na vertente funcional. Deste modo, como já havíamos sinalizado, se em certo momento as teorias funcionalistas descrevem o processo tradutório na tentativa de compreender os fatores que condicionam a tradução, em um momento posterior essas teorias são aplicadas na própria prática tradutória, na busca por traduções que sejam funcionalmente bem-sucedidas:

[...] o funcionalismo faz uso de métodos descritivos (como, por exemplo, análise paralela de textos) para localizar e comparar normas e convenções válidas em variadas comunidades culturais. Já que abordagens funcionalistas têm sido desenvolvidas majoritariamente dentro de instituições acadêmicas voltadas ao treinamento de tradutores, elas são normativas ou avaliativas na medida em que incluem a avaliação de traduções relativas à sua funcionalidade numa dada situação dentro de uma cultura (situation-inculture); futuros tradutores profissionais devem ser treinados não somente para produzir "boas" traduções (isto é, funcionais), satisfazendo as necessidades dos clientes, mas também produzir bons argumentos para defender seus produtos contra críticas injustificáveis de clientes e usuários. (NORD 2007: 2)

Não somente em seu método de análise, mas também em sua tipologia de tradução (cf. NORD 1989), na qual Nord estabelece dois tipos básicos de tradução que se diferem pela função que exercem no contexto de chegada (a tradução documental e a tradução instrumental), percebemos uma aplicação prática das considerações teóricas do funcionalismo. Assim, se a vertente descritiva se atém essencialmente na descrição do fenômeno cultural e social da tradução, vemos na vertente funcional a tentativa de extensão da teoria para prática, o que remonta à própria origem da abordagem funcional, como nos elucida Moreira. Considerando o esquema da disciplina elaborado por Holmes (cf. HoLMES 2004: 172), a abordagem descritiva estaria localizada na vertente "pura" dos Estudos da Tradução, enquanto o funcionalismo ocuparia tanto a vertente "pura" quanto a "aplicada".

Toury faz considerações semelhantes na versão revisada da obra Descriptive Translation Studies and Beyond (2012), na qual aponta para a proximidade das vertentes 
Stervid, B. T. - Do texto ao contexto

descritiva e funcional, a saber, a orientação ao alvo (target-orientedness), e indica a diferença principal entre as duas:

[...] enquanto a maioria dos teóricos funcionalistas ainda vê a justificação final de seu quadro de referência, estabelecido por eles, no desenvolvimento de um modo de lidar com problemas de natureza aplicada que seja mais próximo à realidade, sendo o objeto central fazer melhorias (isto é, mudanças!) no mundo de nossa experiência, meus próprios esforços sempre foram guiados basicamente em direção a um objetivo descritivoexplicativo em prover considerações exaustivas daquilo que tem sido apresentado/visto como tradutório em uma cultura-alvo, a fim de fazer algumas generalizações quanto ao comportamento tradutório. (TOURY 2012: 19-20, tradução nossa)

Neste mesmo comentário, Toury aponta para as contribuições de Nord e a tentativa da teórica "de integrar uma versão da noção de "normas tradutórias", conceito central no pensamento de Toury. Porém, para ele, haveria um distanciamento maior trazido por Nord:

Infelizmente (da perspectiva dos Estudos Descritivos da Tradução), ao fazer isso, Nord (re)introduz o conceito de "lealdade" e como um princípio moral a priori, o que dá um status privilegiado ao que nós chamamos de "adequação". Isso pode ser a abertura de um espaço entre as duas abordagens, visto que o antigo parecia estar se fechando. (TOURY 2012: 20, tradução nossa)

Tendo em vista essa observação, analisaremos a seguir alguns aspectos do conceito de "lealdade" de Nord, como também da noção de "normas de tradução" de Toury, a fim de localizar as ideias centrais que sustentam cada uma das propostas e, então, refletir sobre essa suposta divergência apontada por Toury.

\section{As normas de tradução de Gideon Toury e o conceito de lealdade de Christiane Nord}

O conceito de "normas de tradução" (translational norms) é apresentado por Toury em 1978 no texto The nature and role of norms in translation (cf. TOURY 2004: 198, tradução nossa) e detalhado na obra já citada Descriptive Translation Studies and Beyond, publicada pela primeira vez em 1995 e revisada em 2012. Ele define "normas" como "a tradução de valores ou ideias gerais compartilhadas por uma comunidade, quanto ao que é certo ou errado, adequado ou inadequado, em 'instruções' de desempenho apropriadas para situações concretas e aplicáveis a elas” (2012: 63, tradução nossa). Tais instruções especificariam aquilo que é proibido ou permitido, e seriam, consequentemente, 
Stervid, B. T. - Do texto ao contexto

responsáveis por determinar o uso da língua por uma comunidade nas mais diversas situações, inclusive tradutórias.

A tradução é vista, portanto, como uma atividade governada por normas, assim como as mais variadas atividades exercidas pelo ser humano. Nota-se que já neste ponto podemos ver uma semelhança com as teorias funcionalistas que vai além da orientação ao alvo, "prospectiva": ambas partem da consideração de que a tradução é uma atividade humana e que, portanto, deve possuir aspectos semelhantes a outras atividades. Na abordagem funcional a tradução é tida como uma atividade que tem uma função a ser desempenhada, enquanto o conceito de "normas de tradução" considera outro aspecto também presente nas atividades humanas, isto é, o aspecto normativo.

Se considerarmos esse ponto em comum entre as duas abordagens, parece válido dizer que elas se complementam, oferecendo pontos de vista diferentes sobre a ação tradutória: a intencionalidade (e, em decorrência disso, a funcionalidade) e a normatividade. E como "cada perspectiva permite tipos diferentes de questões a serem feitas", como observa Toury (2012: 670, tradução nossa), cada abordagem segue rumos diferentes, partindo de aspectos igualmente importantes do fenômeno tradutório.

Segundo Toury, normas implicam a necessidade de seleção entre várias alternativas possíveis, que, no caso da tradução, podem corresponder não só às escolhas que o tradutor deve tomar ao longo do processo tradutório, mas até mesmo à decisão de traduzir ou não um texto. Toury propõe dois grupos gerais de normas: normas preliminares (preliminar norms) e normas operacionais (operational norms). O primeiro grupo de normas está relacionado à política de tradução, que é responsável, por exemplo, por determinar a tradução ou não de um texto, bem como se ela será uma tradução direta ou indireta. Já o segundo grupo corresponde às normas que influenciam as decisões tomadas no processo tradutório.

Além desses dois grupos principais, há ainda uma norma inicial (initial norm), que diz respeito às exigências de dois polos, texto/cultura de partida e texto/cultura de chegada. $\mathrm{O}$ tradutor pode tender a uma submissão ao original e às normas que governaram a sua produção, de modo a preocupar-se com a adequação (adequacy), ou tender a aderir às normas da cultura de chegada, buscando uma maior aceitabilidade (acceptability). 
Stervid, B. T. - Do texto ao contexto

Esses dois polos assemelham-se aos dois tipos de tradução na tipologia proposta por Nord (1989), a tradução documental e tradução instrumental. A tradução documental (dokumentarische Übersetzung) tem a função de documentar uma ação comunicativa que ocorreu na cultura de partida e de trazer, ao receptor de chegada, certos aspectos dessa comunicação. Todas as formas de tradução documental (a tradução palavra por palavra ou versão interlinar, tradução literal, filológica e "exotizante") tendem a reforçar aspectos formais do texto de partida, em menor ou maior grau, assemelhando-se ao que Toury chama de "adequação".

Já na tradução instrumental (instrumentelle Übersetzung), a tradução serve de instrumento para se alcançar um novo objetivo comunicativo, sem que o receptor perceba que o texto é uma tradução de outro texto que, por sua vez, já se inseriu em outra situação comunicativa. Assim, aspectos próprios da situação comunicativa do texto de partida não são relevantes para a tradução, a qual pode ter ou não a mesma função que o original. Portanto, esse tipo de tradução segue as normas da cultura receptora, como propõe Toury com o conceito de "aceitabilidade".

Apesar da aproximação possível entre essas duas propostas, vemos que há uma diferença substancial. Para Nord, assim como para os teóricos funcionalistas em geral, o tradutor sempre busca uma aceitabilidade na cultura receptora, mesmo quando produz uma tradução voltada aos aspectos do texto de partida, visto que é a função que o texto vai desempenhar no contexto de chegada que determina essa orientação. Por exemplo, a tradução interlinear, usada em cursos de língua estrangeira nos quais há a necessidade de explicitar categorias gramaticais e estruturas sintáticas, segue palavra por palavra o texto de partida. A tradução filológica, por sua vez, leva a língua de chegada aos limites de aproximação com a língua de partida, já que deve servir de forma intermediária na compreensão do original e pode ser usada, por exemplo, em um contexto universitário. Portanto, segundo uma visão funcional, é sempre a situação em uma dada cultura receptora que determina a orientação adotada pelo tradutor.

Ao lado da funcionalidade (Funktionsgerechtigkeit), tida como objetivo principal do tradutor, a lealdade (Loyalität) também constitui uma exigência a ele. A "lealdade" diz respeito ao compromisso que o tradutor assume perante os vários participantes da ação tradutória, tanto aquele que lhe deu a tarefa de traduzir (Auftraggeber), como 
Stervid, B. T. - Do texto ao contexto

também os receptores do texto (Zieltextempfänger) e o autor do texto de partida (Ausgangstextautor).

De modo a se posicionar contra o paradigma de equivalência, posicionamento adotado numa perspectiva funcional, Nord considera que a relação da tradução com o texto de partida pode se dar de várias formas, já que são diversos os aspectos do original que podem ser enfatizados na tradução, a depender da função a ser exercida por ela. Porém, a função "não deve contrariar a intenção do autor do texto de partida, pelo menos não quando o emissor do texto de partida é também firmado como emissor da tradução na situação de chegada" (NORD 1989: 102, tradução nossa), o que é também esperado dos próprios clientes e receptores da tradução.

Vale acentuar que, para Nord, a "intenção" não deve ser entendida como algo acessível diretamente, mas como algo sobre o qual podemos obter algumas informações a partir da análise dos aspectos intra e extratextuais (cf. NORD 2009). Além disso, ela não defende a manutenção da intenção do autor, como seria em uma abordagem "retrospectiva", nem mesmo a sua possibilidade, mas apenas a consideração dessa intenção, analisada da perspectiva do tradutor, a fim de que a tradução não vá a uma direção contrária a ela. Deste modo, levar em conta a suposta intenção do emissor não está relacionado com a busca por fidelidade, mas sim por lealdade.

Assim, ao formular a noção de lealdade, Nord propõe uma alternativa à noção de fidelidade, que estaria relacionada a um conceito tradicional de tradução segundo o qual é esperado que ela seja "fiel”, isto é, "equivalente" ao texto de partida (1989: 100-101, tradução nossa). Deixando clara a diferença entre lealdade e fidelidade, a autora explica: "Lealdade é uma categoria ética na convivência entre os seres humanos, enquanto 'fidelidade', no contexto de uma tradução, designa uma relação de imitação entre textos" (2009: 31, tradução nossa).

Não se trata, portanto, de uma reintrodução de um conceito tal qual o de fidelidade, como aludiu Toury, mas sim da proposta de considerar as responsabilidades do tradutor perante todos que de alguma forma possuem alguma relação e expectativa quanto à tradução: ao invés de uma fidelidade ao texto original, propõe-se que deva haver lealdade (ou seja, responsabilidades) em relação às pessoas envolvidas no processo tradutório. Isso significa que o tradutor deve considerar os interesses dos agentes inseridos no contexto 
Stervid, B. T. - Do texto ao contexto

de partida e chegada. Desta forma, também não se verifica com esse conceito um "status privilegiado" da "adequação", já que a lealdade não se refere somente ao autor do texto de partida, mas igualmente aos receptores do texto de chegada.

Por estar diretamente engajada na formação de tradutores, Nord propõe seu conceito de lealdade tendo justamente em vista a prática tradutória, de modo a oferecer a atuais e futuros tradutores orientações que tangem inclusive questões de fundo ético, ao apontar para a necessidade de se ter em conta o compromisso firmado com as instâncias da cultura receptora. Assim como qualquer reflexão sobre prática tradutória que tenha como objetivo estabelecer diretrizes ao tradutor, há, inevitavelmente, algum grau de "retrospectividade", ou seja, de consideração de aspectos da cultura e do texto de partida. Porém, diferentemente do conceito de fidelidade, aplicado na análise e crítica de traduções, a lealdade diz respeito a compromissos entre pessoas, não sendo possível aplicá-la à descrição de traduções, o que talvez tenha gerado o mal-entendido de Toury.

Para Nord, uma tradução deve ser "funcionalmente justa" (funktionsgerecht) e ao mesmo tempo ter algum tipo de ligação com o texto de partida. Assim, ela define tradução como:

a produção de um texto de chegada funcionalmente justo [funktionsgerecht], em ligação com um dado texto de partida, na qual essa ligação pode ser especificada de diversas formas, a depender do skopos de translação (da função, almejada ou exigida, do texto de chegada) (NORD 1989: 102, tradução nossa).

Desta forma, a tradução depende da compatibilidade entre o escopo da tradução e o texto de partida, o que é específico de cada cultura. Segundo Nord (1989: 102), é até mesmo possível que uma incompatibilidade entre eles impossibilite que haja tradução. Para Toury (2012: 26), diferentemente, tradução é aquilo que é pressuposto como tal (cunhando o termo assumed translation), de modo que o que interessa à sua pesquisa não é se a tradução de fato contempla aspectos do texto-alvo e se há uma relação de semelhança entre os dois textos, mas sim que se suponha essa relação.

Segundo Dizdar, Toury assume uma postura crítica em relação às definições de tradução, visto que à maioria subjaz a ideia de tradução como a reconstrução perfeita e máxima do texto de partida ou tradução como troca de sistema linguístico, partindo-se do pressuposto "de uma tradução potencial, de um tipo de constructo abstrato que deve ser realizado e servir de medida para a avaliação do verdadeiro produto". Essa ideia seria, 
Stervid, B. T. - Do texto ao contexto

para Toury, o motivo pelo qual traduções são ditas como insuficientes ou "erradas", já que "nenhuma tradução pode corresponder a tal ideia preconcebida, a qual se orienta em critérios linguísticos e na supremacia do texto de partida" (DIZDAR 2006: 310, tradução nossa). Assim, segundo Dizdar, o conceito de assumed translation de Toury seria "uma disposição à abertura e à indecisão" (2006: 326, tradução nossa).

Tendo em vista que o principal objetivo tanto da tipologia de Nord quanto de seu conceito de lealdade é orientar o tradutor em sua prática tradutória, a definição de tradução proposta por Toury não poderia contribuir para esse objetivo, porquanto não oferece ao tradutor as diretrizes das quais necessita. Ao buscar oferecer aos tradutores em formação uma definição de tradução (bem-sucedida), Nord aponta para os dois aspectos mencionados (funcionalidade e lealdade), o que muito difere da antiga concepção de boa tradução como aquela que é "fiel", ou seja, "equivalente".

Se considerarmos que há lealdade quando o tradutor considera as expectativas dos agentes participantes, adequando-se às normas da cultura receptora e considerando a função que o texto exercerá, então novamente temos uma aproximação entre as duas perspectivas. Portanto, a nosso ver, não se trata de pontos de vistas divergentes, mas sim de interesses e propósitos diferentes: enquanto Nord tem como principal objetivo elaborar uma teoria que possa ser aliada à prática, Toury, como vimos, procura compreender e descrever a tradução como fenômeno sociocultural, não levando em conta responsabilidades ou diretrizes na prática tradutória.

\section{Aplicação nas pesquisas sobre tradução}

Com o intuito de ter uma visão mais acurada da aplicação das teorias funcionalistas e descritivistas em pesquisas acadêmicas, realizamos uma análise de teses e dissertações produzidas no Departamento de Letras Modernas (DLM) da Universidade de São Paulo (USP), entre os anos de 2006 e 2018, disponíveis na "Biblioteca Digital de Teses e Dissertações". Primeiramente, selecionamos as pesquisas sobre tradução, com ou sem interface direta aos Estudos da Tradução, das cinco áreas do departamento ${ }^{3}$. Em seguida,

\footnotetext{
${ }^{3} \mathrm{Na}$ área de Língua e Literatura alemã foram encontradas 19 pesquisas sobre tradução em um total de 109; na área de Língua espanhola e Literaturas Espanhola e Hispano-Americana, 20 de 204; Língua e Literatura Francesa/Estudos Linguísticos, Literários e Tradutológicos em Francês, 25 de 226; Estudos Linguísticos
} 
Stervid, B. T. - Do texto ao contexto

verificamos se há, em cada pesquisa, citações atribuídas a algum teórico que se enquadra a uma das abordagens de nosso estudo, com objetivo de verificar com mais precisão o quão presente elas se encontram nas pesquisas dessa instituição. Por fim, verificamos qual a abordagem principal utilizada, bem como o tipo de pesquisa, com base no mapeamento proposto por Williams e Chesterman (2002).

Assim, localizamos noventa pesquisas, em um total de 169 (portanto, 53,2\%), que citam pelo menos um teórico ligado a uma das abordagens. Observamos que as teorias da abordagem descritiva estão mais presentes que as teorias funcionalistas: em 67 pesquisas $(39,6 \%)$ encontramos referências a teóricos ligados à vertente descritiva e em 41 (24\%), referências a teóricos da vertente funcional. Com isso, podemos dimensionar a presença das duas abordagens na instituição: trata-se de abordagens que contribuem com um pouco mais da metade das pesquisas, o que é significativo, se levarmos em conta o fato de que nem todas as pesquisas analisadas partem dos pressupostos dos Estudos da Tradução, orientando-se, por vezes, mais ao viés da Linguística ou dos Estudos Literários.

Porém, resta-nos ainda lançar um olhar mais profundo para a aplicação das teorias, a fim de compreendermos como elas estão sendo utilizadas na pesquisa acadêmica e se o modo de as aplicar nos revela algo sobre as peculiaridades de cada abordagem ou mesmo de seus pontos de aproximação. Para tanto, selecionamos apenas os trabalhos nos quais há o uso das abordagens descritiva e/ou funcional como aporte teórico principal, ou seja, nos quais as teorias foram não somente citadas em alguma parte do texto, mas serviram como norteadoras de toda a pesquisa. Assim, verificamos que 29 pesquisas $(17,1 \%)$ têm como principal aporte teórico teorias descritivistas, 11 (6,5\%) partem de uma abordagem funcional e apenas quatro integram as duas vertentes $(2,4 \%)$.

$\mathrm{Na}$ análise da aplicação das teorias, partimos das áreas de pesquisa em Estudos da Tradução descritas por Williams e Chesterman (2002), a saber: Análise textual e tradução, Avaliação de qualidade de tradução, Tradução de gênero, Multimídia, Tradução e tecnologia, História da Tradução, Ética de tradução, Terminologia e glossários, Interpretação, Processo de tradução, Formação de tradutores e Profissão.

e Literários em Inglês, 52 de 327; Língua e Literatura Italiana/Língua, Literatura e Cultura Italianas, 17 de 126; e por fim, 36 pesquisas na área dos Estudos da Tradução. Analisamos, portanto, um total de 169 pesquisas.

Pandaemonium, São Paulo, v. 23, n. 39, jan.-abr. 2020, p. 1-24 
Stervid, B. T. - Do texto ao contexto

Assim, conseguimos localizar cinco tipos de pesquisa que se baseiam em teorias descritivistas e/ou funcionalistas, em parte semelhantes à divisão acima:

1. Tradução comentada: este tipo de pesquisa se insere na área de Análise textual e tradução (Text Analysis and Translation. cf. WiLliams e CHESTERMAN 2002) e tem por objetivo a produção de uma tradução a partir de um estudo aprofundado do texto a ser traduzido, bem como de uma fundamentação teórica que servirá de base para as escolhas de tradução. São apresentados, além da tradução, comentários que justificam as estratégias adotadas e que esclarecem o próprio processo tradutório (Ex.: SCHÄFER 2015).

2. Tradução de gênero (Genre Translation. cf. WiLliAMS e CHESTERMAN 2002): esta área engloba pesquisas que se concentram na investigação das especificidades de tradução de algum gênero textual, literário ou não, como poesia, prosa, drama, literatura infantil, textos jurídicos, científicos etc. (Ex.: VIDAL 2018).

3. História da tradução (Translation History. cf. WILliAMS e CHESTERMAN 2002): nesta categoria se inserem as pesquisas que têm como objetivo investigar aspectos histórico-culturais ligados à tradução/adaptação. Trata-se, majoritariamente, de estudos sobre recepção que procuram compreender suas condicionantes culturais e a atuação dos agentes que participam dela. Essas pesquisas podem ter como enfoque os próprios tradutores em seus contextos socioculturais, a escolha de textos para tradução em determinada época e cultura ou mesmo a relação entre estratégia de tradução e aspectos extralinguísticos, podendo partir de perguntas como "Quem? O quê? Por quê? E Como?” (2002: 16). Incluímos nesta categoria tanto as pesquisas que investigam, de forma aprofundada, aspectos da recepção sob um viés histórico (Ex.: CASTRO 2013), como também aquelas em que o estudo sobre o contexto histórico-cultural precede uma análise textual de uma ou mais traduções (Ex.: COBElo 2015).

4. Terminologia e glossários (Terminology and Glossaries. cf. WiLliams e CHESTERMAN 2002: 20): trata-se de pesquisas que visam à identificação de termos próprios de determinado domínio (aviação, futebol, música, turismo 
Stervid, B. T. - Do texto ao contexto

etc.), a partir da análise de um corpus bilíngue, principalmente à luz da Linguística de Corpus. (Ex.: SANTOS 2017; FuCHS 2018).

5. Estudo de cunho teórico: pesquisas que propõem uma discussão ou revisão de alguma teoria ou investigam o desenvolvimento de alguma vertente dos Estudos da Tradução. Aqui as teorias funcionalistas e descritivistas constituem o próprio objeto de investigação (Ex.: MoREIRA 2014).

\begin{tabular}{|l|c|c|c|c|}
\hline & Descritiva & Funcional & $\begin{array}{l}\text { Descritiva e } \\
\text { Funcional }\end{array}$ & Total \\
\hline 1. Tradução comentada & 0 & 6 & 2 & 8 \\
\hline 2. Tradução de gênero & 3 & 2 & 0 & 5 \\
\hline 3. História da tradução & 24 & 1 & 2 & 27 \\
\hline 4. Terminologia e glossário & 1 & 1 & 0 & 2 \\
\hline 5. Estudo de cunho teórico & 1 & 1 & 0 & 2 \\
\hline Total & 29 & 11 & 4 & 44 \\
\hline
\end{tabular}

Tabela 1. Relação entre abordagem principal e tipo de pesquisa

A tabela acima mostra que as teorias descritivistas são aplicadas principalmente na área de História da tradução, que engloba o estudo da recepção de obras literárias, bem como a análise textual de traduções e de suas condicionantes culturais. Como exemplo, podemos citar a pesquisa de Quirino (2012), que investiga o perfil de tradutores responsáveis pelas traduções de obras de James Joyce no Brasil, com o objetivo de localizar o que está por trás das diferenças entre as diversas formas de traduzir e traçar uma relação entre os tradutores e o desenvolvimento de teorias de tradução literária no país. Neste caso, os conceitos de "reescrita" e "patronagem", de Lefevere, contribuíram para o estudo da atuação destes tradutores na reescrita das obras.

Em outros casos, teorias descritivistas também foram empregadas em pesquisas voltadas para a análise textual de diversas traduções de um mesmo texto-fonte, realizada com base em um estudo prévio dos aspectos do contexto de recepção, como na tese de Hanna (2016), que analisa quatro traduções brasileiras de Watchman e parte de um estudo 
Stervid, B. T. - Do texto ao contexto

da inserção das histórias em quadrinhos no sistema literário brasileiro, a partir da teoria de "polissistemas" de Even-Zohar e do conceito de "patronagem" de Lefevere.

A partir das teorias descritivistas, como vimos, é realizado o estudo do fenômeno tradutório no contexto da cultura receptora através de estudos de caso de natureza descritiva e empírica. Em relação ao estudo de recepção de literatura brasileira na Alemanha, foram realizadas pesquisas como as de Castro (2013) e de Nascimento (2016) sobre a recepção da obra de Clarice Lispector e de Carolina Maria de Jesus, respectivamente. Tais pesquisas tiveram como objetivo comum o mapeamento das condições de recepção das obras citadas através da análise de resenhas críticas sobre as traduções. A partir daí, foram localizados "eixos ou tendências críticas empregados pelos articulistas na tentativa de acomodarem as obras traduzidas no sistema literário alemão" (AZENHA JUNIOR 2017: 80). Como aporte teórico, as pesquisas citadas utilizam das teorias já apontadas nesse artigo: a "teoria dos polissistemas", elaborada por Even-Zohar, a noção de "reescrita" e "patronagem" de Lefevere (1992) e a noção de "normas de tradução" de Toury (2012).

Apesar de a maioria dos trabalhos analisados que têm por objetivo descrever traduções e sua recepção não adotar uma perspectiva funcional, tendo em vista a diferença de propósitos, como procuramos demonstrar, a teoria do escopo de Vermeer serviu de principal aporte teórico a um estudo de caráter historiográfico sobre a localização de videogames no Brasil (SouZA 2015). Esta pesquisa não se concentrou somente nos aspectos histórico-culturais da recepção, mas também contou com uma análise das estratégias de tradução, a partir de uma visão funcional sobre os diversos elementos da situação "comunicativa", como os receptores de chegada.

Em outros trabalhos, as teorias funcionalistas, embora não sirvam de embasamento principal da pesquisa, são conjugadas à abordagem descritiva, de modo a complementar o entendimento dos fatores da recepção que exercem influência na tradução, como na pesquisa de Nascimento (2016). Também pudemos localizar pesquisas que integram as abordagens descritiva e funcional, ambas como principal aporte teórico, o que aponta mais uma vez para a compatibilidade já verificada através da análise das teorias. Um exemplo disso é a pesquisa de Bertin (2008), que analisa "reescrituras" de peças de Shakespeare, com base na discussão dos limites da tradução e da adaptação, articulando o conceito de "reescrita" de Lefevere e a teoria do escopo de Vermeer.

Pandaemonium, São Paulo, v. 23, n. 39, jan.-abr. 2020, p. 1-24 
Stervid, B. T. - Do texto ao contexto

Como esperado, a aplicação das teorias funcionalistas é mais frequente em trabalhos de tradução comentada, tanto de texto literário (Toledo 2016) quanto de especialidade (LIM 2011), o que se deve à aproximação da abordagem funcional com a prática tradutória. Também nesse tipo de pesquisa encontramos a integração das abordagens funcional e descritiva: na pesquisa de Oliveira (2017), na qual é realizada uma proposta de tradução musicada de poemas de Langston Hughes, é realizado um estudo da recepção do autor no Brasil, a partir de teorias funcionalistas (teoria do escopo, de Vermeer) e descritivistas (teoria dos polissistemas, de Even-Zohar, e conceito de refração, de Lefevere), para que a tradução fosse conduzida de acordo com essa contextualização prévia.

Em muitas das pesquisas de tradução comentada analisadas, o modelo de análise textual proposto por Nord é utilizado na análise do texto a ser traduzido e no estabelecimento das diretrizes de tradução, que leva em conta os aspectos da situação comunicativa e do contexto de chegada (LIM 2011; SCHÄFER 2015; UTIDA 2016). Por outro lado, o mesmo modelo pode ser igualmente aplicado em análises de traduções, como demonstram algumas pesquisas realizadas em outras instituições, como, por exemplo, a dissertação de Meneghel (2015), do Programa de Pós-Graduação em Estudos da Tradução da Universidade Federal de Santa Catariana, na qual é feita uma análise funcional da tradução brasileira da obra The Years de Virginia Woolf, a partir do modelo de Nord.

Portanto, percebe-se que tanto as teorias funcionalistas quanto as descritivistas, mesmo que uma seja mais aplicada na prática de tradução e a outra, em descrições e estudos de caso, são suficientemente maleáveis para a aplicação em diferentes tipos de pesquisa. Cabe, todavia, o questionamento sobre se as pesquisas que partiram da abordagem funcional teriam chegado às mesmas conclusões se tivessem se pautado na abordagem descritiva. Uma futura investigação mais aprofundada sobre a aplicação das teorias na pesquisa acadêmica poderá contribuir para uma melhor compreensão dessa questão. De todo modo, o que fica evidente na análise das pesquisas é o enfoque dado ao contexto de chegada (e não exclusivamente ao texto de partida), comum a todas elas. Com isso, podemos concluir que o fato de ambas as abordagens serem prospectivas, voltadas ao contexto de recepção, contribui para que suas teorias sejam facilmente conjugadas. 


\section{Considerações finais}

A análise das teorias funcionalistas e descritivistas aponta para um foco comum dado ao contexto de recepção e aos agentes que atuam no processo tradutório, de modo a se distanciarem das abordagens que tinham como objeto de interesse apenas o texto, desconsiderando aspectos extralinguísticos. Dizdar comenta que tanto em Vermeer quanto em Toury há crítica à crença de um significado imanente ao texto, crítica que se expressa, em suas teorias, como "recusa de teorias linguísticas e como descentralização da linguística" (2006: 328, tradução nossa). Há, portanto, com as duas abordagens um afastamento do conceito de equivalência em tradução.

Percebemos, porém, que as vertentes partem de objetivos diversos: enquanto a abordagem descritiva procura compreender questões relacionadas à posição da tradução numa dada cultura e seu funcionamento como fenômeno, a abordagem funcional tem como principal interesse a crítica de tradução e a formação de tradutores. Por outro lado, a aplicação das teorias funcionalistas nas pesquisas de mestrado e doutorado em instituições acadêmicas não se restringe aos trabalhos nos quais é necessária a união da teoria e prática, como os trabalhos de tradução comentada: nota-se que também em análise descritiva de traduções há o uso das teorias funcionalistas em seu aporte teórico.

Da mesma forma, como aponta Dizdar, as teorias descritivistas também podem contribuir para a formação de tradutores, visto que ajudam na conscientização do tradutor sobre a ação tradutória. Assim, as normas de tradução de Toury podem ser "transformadas em um instrumento de bricolagem para os objetivos de uma didática da tradução" (2006: 328 , tradução nossa). Portanto, tendo como base a mesma orientação prospectiva, as abordagens funcional e descritiva apresentam vários pontos de contato que lhes dão uma flexibilidade na aplicação e na conjugação de suas teorias.

\section{Referências bibliográficas}

AZENHA JUNIOR, João. Transferência cultural em tradução: contextualização, desdobramentos, desafios. Tradterm, v. 16, 2010, p. 37-66.

AZENHA JUNIOR, João. Clarice, Carolina e a Alemanha: reverberações da literatura brasileira traduzida. Todas as Letras, São Paulo, v. 19, n. 3, 2017, p. 78-93.

Pandaemonium, São Paulo, v. 23, n. 39, jan.-abr. 2020, p. 1-24 
Stervid, B. T. - Do texto ao contexto

BERTIN, Marilise Rezende. Traduções, adaptações, apropriações: reescrituras das peças Hamlet, Romeu e Julieta e Otelo, de William Shakespeare. 2008. Dissertação (Mestrado em Estudos Linguísticos e Literários em Inglês) - Faculdade de Filosofia, Letras e Ciências Humanas, Universidade de São Paulo, São Paulo, 2008.

CAStro, Thales Augusto Barreto de. Um outro olhar sobre a literatura brasileira: Clarice Lispector em tradução alemã. 2013. Dissertação (Mestrado em Letras) - Faculdade de Filosofia, Letras e Ciências Humanas, Universidade de São Paulo, São Paulo, 2013.

CoBelo, Silvia B. As adaptações do Quixote no Brasil (1886-2013): uma discussão sobre retraduções de clássicos da literatura infantil e juvenil. 2015. Tese (Doutorado em Espanhol e Literaturas Espanhola e Hispano-americana) - Faculdade de Filosofia, Letras e Ciências Humanas, Universidade de São Paulo, São Paulo, 2015.

CRUZ, Celso Donizete. O trabalho do tradutor: em busca de uma teoria para a prática. 2012. Tese (Doutorado em Letras) - Faculdade de Filosofia, Letras, Ciências Humanas, Universidade de São Paulo, São Paulo, 2012.

DIZDAR, Dilek. Translation: Um- und Irrwege. Berlin: Frank \& Timme, 2006.

Even-Zohar, Itamar. Teoria dos polissistemas. Tradução de Luis Fernando Marozo, Carlos Rizzon e Yanna Karlla Cunha. Revista Translatio, Porto Alegre, n. 5, 2013, p. 2-21.

FuCHS, Sandra Navarro. Orientações culturais e suas implicações para a tradução funcionalista: um estudo na área do turismo à luz da Linguística de Corpus. 2018. Tese (Doutorado em Estudos da Tradução) - Faculdade de Filosofia, Letras e Ciências Humanas, Universidade de São Paulo, São Paulo, 2018.

HannA, Katia Regina Vighy. Do gibi ao livro: as traduções de Watchmen no Brasil. 2016. Tese (Doutorado em Estudos Linguísticos e Literários em Inglês) - Faculdade de Filosofia, Letras e Ciências Humanas, Universidade de São Paulo, São Paulo, 2016.

HeRmans, Theo. Translation Studies and a new paradigm. In: Hermans, Theo (ed.). The Manipulation of Literature: studies in literary translation. London: Croom Helm, 1985, p. 7-15.

HERMANS, Theo. Translation in systems: descriptive and system-oriented approaches explained. Manchester: St. Jerome Publishing, 1999. (Series: Translation Theories Explained 7).

HoLMES, James. The name and nature of Translation Studies. In: VENUTI, Lawrence (org.). The Translation studies reader. Nova York: Routledge, 2004, p. 172-185.

LEFEVERE, André. Translation, rewriting and the manipulation of literary fame. London: Routledge, 1992.

LiM, Lana. Festin Joyeux, ou, la Cuisine en Musique, de J. Lebas: tradução de receitas em versos na corte de Luís XV. 2011. Dissertação (Mestrado em Letras) - Faculdade de Filosofia, Letras e Ciências Humanas, Universidade de São Paulo, São Paulo, 2011.

MENEGHEL, Janaina Freire. Uma análise funcionalista: como a influência londrina na obra The Years, de Virgínia Wolf, se apresenta na tradução brasileira Os Anos. 2015. Dissertação (Mestrado em Estudos da Tradução) - Pós-Graduação em Estudos da Tradução, Universidade Federal de Santa Catarina, Florianópolis, 2015.

MOREIRA, Marcelo Victor de Souza. Estudos funcionais da tradução: rupturas e continuidades. 2014. Dissertação (Mestrado em Letras) - Faculdade de Filosofia, Letras e Ciências Humanas, Universidade de São Paulo, São Paulo, 2014.

MUNDAY, Jeremy. Introducing Translation Studies: theories and applications. London: Routledge, 2008.

Pandaemonium, São Paulo, v. 23, n. 39, jan.-abr. 2020, p. 1-24 
Stervid, B. T. - Do texto ao contexto

NASCimento, Raquel Alves dos Santos. Do exotismo à denúncia social: sobre a recepção de Quarto de Despejo, de Carolina Maria de Jesus, na Alemanha. 2016. Dissertação (Mestrado em Estudos da Tradução) - Faculdade de Filosofia, Letras e Ciências Humanas, Universidade de São Paulo, São Paulo, 2016.

NORD, Christiane. Loyalität statt Treue: Vorschläge zu einer funktionalen Übersetzungstypologie. Lebende Sprachen, Leipzig, v. 34, issue 89, 1989, p. 100-105.

NORD, Christiane. Translation as a purposeful activity: functionalist approaches explained. Manchester: St. Jerome Publishing, 2007.

NORD, Christiane. Textanalyse und Übersetzen: Theoretische Grundlagen, Methode und didaktische Anwendung einer übersetzungsrelevanten Textanalyse. Tübingen: Julius Groos Verlag, 2009.

OliveIRA, Pedro Tomé de Castro. Os Blues Poems de Langston Hughes: por uma tradução musicada. 2017. Dissertação (Mestrado em Estudos da Tradução) - Faculdade de Filosofia, Letras e Ciências Humanas, Universidade de São Paulo, São Paulo, 2017.

PYM, Anthony. Explorando teorias da tradução. São Paulo: Perspectiva, 2017.

QUIRINO, Maria Teresa. Retratos de tradutores de James Joyce como agentes da tradução literária no Brasil: um estudo de caso. 2012. Tese (Doutorado em Estudos Linguísticos e Literários em Inglês) - Faculdade de Filosofia, Letras e Ciências Humanas, Universidade de São Paulo, São Paulo, 2012.

REISS, Katharina; VERMEER, Hans J. Towards a general theory of translational action: skopos theory explained. Nova York: Routledge, 2014.

SANTOS, Gabriela Pereira dos. Glossário bilíngue português-inglês de colocações especializadas de Harmonia Musical, baseado em corpus. 2017. Dissertação (Mestrado em Estudos da Tradução) - Faculdade de Filosofia, Letras e Ciências Humanas, Universidade de São Paulo, São Paulo, 2017.

SCHÄFER, Anna Carolina. Quando a tradução (re)conta a História: análise textual e tradução comentada de interrogatórios da "Rosa Branca". 2015. Dissertação (Mestrado em Língua e Literatura Alemã) - Faculdade de Filosofia, Letras e Ciências Humanas, Universidade de São Paulo, São Paulo, 2015.

SNELL-HoRnBy, Mary. The Turns of Translation Studies: new paradigms or shifting viewpoints? Amsterdam: John Benjamins Publishing Co., 2006.

Snell-Hornby, Mary; HöNIG, Hans G.; KusSMAul, P.; SCHMitT, Peter A. (org.). Handbuch Translation. Tübingen: Stauffenburg, 2015.

SoUZA, Ricardo Vinicius Ferraz de. Tradução e videogames: uma perspectiva histórico-descritiva sobre a localização de games no Brasil. 2015. Dissertação (Mestrado em Estudos da Tradução) - Faculdade de Filosofia, Letras e Ciências Humanas, Universidade de São Paulo, São Paulo, 2015.

TOLEDO, Fernando Martins de. Por outros olhos: alteridade em tradução de (e em) Rafik Schami. 2016. Dissertação (Mestrado em Estudos da Tradução) - Faculdade de Filosofia, Letras e Ciências Humanas, Universidade de São Paulo, São Paulo, 2016.

TOURY, Gideon. The nature and role of norms in translation. In: VENUTI, Lawrence (org.). The Translation studies reader. Nova York: Routledge, 2004, p. 198-211.

TOURY, Gideon. Descriptive translation studies and beyond. Amsterdam: John Benjamins Publishing Co., 2012.

Pandaemonium, São Paulo, v. 23, n. 39, jan.-abr. 2020, p. 1-24 
Stervid, B. T. - Do texto ao contexto

UTIDA, Yasmin Cobaiachi. Tradução e memória: a legendagem de um filme-testemunho sobre a Rosa Branca. 2016. Dissertação (Mestrado em Língua e Literatura Alemã) - Faculdade de Filosofia, Letras e Ciências Humanas, Universidade de São Paulo, São Paulo, 2016.

VIDAL, Aline Gomes. Entre o gênero e a norma: uma análise dialógico-discursiva da tradução inglesa do best-seller de aconselhamento O vendedor de sonhos, de Augusto Cury. 2018. Dissertação (Mestrado em Estudos da Tradução) - Faculdade de Filosofia, Letras e Ciências Humanas, Universidade de São Paulo, São Paulo, 2018.

Williams, Jenny; CheSTERMAn, Andrew. The map: a beginner's guide to doing research in translation studies. Manchester: St. Jerome Publishing, 2002. 